\title{
Limited genetic diversity and high differentiation among the remnant adder (Vipera berus) populations in the Swiss and French Jura Mountains
}

\author{
Sylvain Ursenbacher · Jean-Claude Monney • \\ Luca Fumagalli
}

Received: 31 May 2007/ Accepted: 26 March 2008/Published online: 6 April 2008

(C) Springer Science+Business Media B.V. 2008

\begin{abstract}
Although the adder (Vipera berus) has a large distribution area, this species is particularly threatened in Western Europe due to high habitat fragmentation and human persecution. We developed 13 new microsatellite markers in order to evaluate population structure and genetic diversity in the Swiss and French Jura Mountains, where the species is limited to only a few scattered populations. We found that $V$. berus exhibits a considerable genetic differentiation among populations (global $\mathrm{F}_{\mathrm{ST}}=$ 0.269 ), even if these are not geographically isolated. Moreover, the genetic diversity within populations in the Jura Mountains and in the less perturbed Swiss Alps is significantly lower than in other French populations, possibly due to post-glacial recolonisation processes. Finally, in order to minimize losses of genetic diversities within isolated populations, suggestions for the conservation of this species in fragmented habitats are proposed.
\end{abstract}

S. Ursenbacher · L. Fumagalli

Laboratoire de Biologie de la Conservation, Département d'Ecologie et Evolution, Biophore, Université de Lausanne, 1015 Lausanne, Switzerland

S. Ursenbacher

School of Biological Sciences, University of Wales,

Bangor LL27 2UW, UK

\section{S. Ursenbacher $(\square)$}

Department of Environmental Sciences, Section of Conservation Biology, University of Basel, St. Johanns-Vorstadt 10, 4056 Basel, Switzerland

e-mail: s.ursenbacher@unibas.ch

J.-C. Monney

Centre de Coordination pour la protection des Amphibiens et des Reptiles de Suisse (KARCH), Passage Maximilien-de-Meuron 6, 2000 Neuchatel, Switzerland
Keywords Population genetic structure . Jura Mountains · Microsatellite - Snake · Vipera berus

\section{Introduction}

Due to human pressure, particularly habitat destruction, many species are declining worldwide, providing a major concern for conservation biologists (Caughley 1994; Allendorf and Luikart 2007). Whereas some species have faced rapid extinction, the majority suffer from the consequences of habitat fragmentation and reduction of their population size, resulting in loss of genetic diversity, which can lead to a decrease of their adaptive potential, as well as in an increase of inbreeding (Frankham 1995, 2005; Leimu et al. 2006). Indeed, population genetic theory predicts that small populations and isolated demes should show a lower level of genetic variability due to genetic drift and/or inbreeding (Hartl and Clark 1997), and this prediction has often been confirmed in threatened species (for a review, see Frankham 1996). Consequently, these small and isolated populations suffer from a high risk of local extinction. A fundamental tenet of conservation biology is to identify where conservation efforts must be applied in order to develop effective management strategies (see Soulé 1986; Frankham et al. 2002).

Amongst vertebrates, extinction risks are particularly pronounced for reptiles, which have been listed as protected in many countries (e.g. Corbett 1989; Hofer et al. 2001). Indeed, snakes and particularly venomous species have undergone considerable persecution, often encouraged by local governments during the 19th and the 20th centuries in most western European countries. Like large carnivores such as wolf and lynx, vipers were decimated by this persecution and several populations were completely 
eradicated. For instance, during 27 years around 570,000 vipers (Vipera aspis and V. berus) were killed in three departments of eastern France (Kaufmann 1893). In addition fragmentation of their habitat resulting from human activities increases the threat. All these factors had a considerable impact on population fragmentation, by isolating small demes and, consequently, leading to stochastic genetic processes such as genetic drift and inbreeding, as documented in a small and isolated population of adders in Sweden (Madsen et al. 1996).

Only a few studies have been published to date that use molecular techniques to investigate snake population genetic structure at a local scale. For example, in the black rat snake (Elaphe obsoleta; Lougheed et al. 1999), microsatellite markers did not detect any structuring between hibernacula separated by a few kilometres. The northern water snake (Nerodia sipedon) also showed a low, yet significant, genetic differentiation among populations separated by about $1.5 \mathrm{~km}$ (Prosser et al. 1999). However, the timber rattlesnake (Crotalus horridus) displayed a high level of phylopatry, with genetic distances between hibernacula being larger and significant in 50\% of the comparisons (Villarreal et al. 1996). Within the massasauga rattlesnake (Sistrurus c. catenatus), microsatellites markers revealed a huge differentiation between populations (Gibbs et al. 1997), whereas RAPD analyses did not show any structure between the same populations (Gibbs et al. 1994; see also Gibbs et al. 1997 for the comparison). Also based on RAPD, Jäggi et al. (2000) demonstrated a low genetic differentiation within asp viper (V. aspis) populations in the Jura Mountains. At a lower scale, a recent study on the timber rattlesnake (Clark et al., 2008) exhibited only modest levels of differentiation between hibernacula, no relationship between genetic differentiation and geographic distance, but rather with cost-based distance, as well as high levels of philopatry for both sexes.

The adder ( $V$. berus) is the terrestrial snake with the largest distribution (Saint Girons 1980). However, this species is locally extremely threatened, particularly in Western Europe, where habitat fragmentation is substantial (Castanet and Guyetant 1989; Völkl and Thiesmeier 2002). Despite their strong isolation, several size-limited populations have been able to subsist during decades in small areas of only a few hectares (Monney and Ursenbacher, pers. obs.) without obvious signs of inbreeding depression (but see Madsen et al. 1996). In addition, limited dispersal (Viitanen 1967; Prestt 1971; Neumeyer 1987; Monney 1996) and high phylopatry (Madsen and Shine 1992; Luiselli 1993) of adult vipers suggests that this species should show pronounced genetic differentiation among populations. Nevertheless, adders have a secretive behaviour and the extent of offspring migration remains unknown in spite of the preliminary study of Saint Girons (1981).
In the Jura Mountains (an area of about $20,000 \mathrm{~km}^{2}$ between France and Switzerland), the adder is considered as particularly vulnerable, since only 51 locations harbouring adders have been recorded (45 in France, five in Switzerland, see Pinston et al. 2000; Hofer et al. 2001). However, not all these populations are viable and several comprise only a few individuals (Pinston et al. 2000). Moreover, most of these populations are isolated from each other by unsuitable habitat, and only one region still comprises several interconnected populations (humid zone of the Drugeon's basin; Pinston et al. 2000).

The genetic consequences of habitat fragmentation on adder populations are unknown. Effective conservation strategies require the identification of biologically relevant units within species as the focus of management and legal protection efforts. Hence, it is important to assess the levels of genetic variability and differentiation among the remnant adder populations in the Jura Mountains. In this study we developed new microsatellites markers in order to estimate the genetic diversity within and among remnant populations of $V$. berus. Levels of genetic diversity and differentiation in additional populations that did not suffer from major anthropogenic activities during the last decades (Swiss Alps and France) were also estimated and compared with the studied populations. We tested the prediction of a positive correlation (see Frankham 1996) between current population size, effective population size and genetic variation (allelic richness). In addition, we attempted to identify geographical barriers resulting from pronounced genetic discontinuities between populations. Ultimately, results are discussed with respect to their implication for conservation of $V$. berus populations.

\section{Material and methods}

\section{Sampling and DNA extraction}

We analysed a total of 285 adders originating from ten of the largest populations in the Jura Mountains at the border between France and Switzerland (see Pinston et al. 2000; Hofer et al. 2001). In addition, 65 animals from three populations located in the Swiss Alps, 23 individuals from two populations of the Massif Central (France) and 19 individuals from one population in the region of Rennes (France) were collected (Fig. 1). The term population in our study corresponds to samples collected less than $500 \mathrm{~m}$ from each other. Geographically close populations (between 1.5 and $3.5 \mathrm{~km}$ ) are considered as a population group (e.g. FR1, FR2 and FR3). All captured animals were measured, weighted, marked by scale-clipping or with microchips (DataMars SA, Lugano, Switzerland) and 


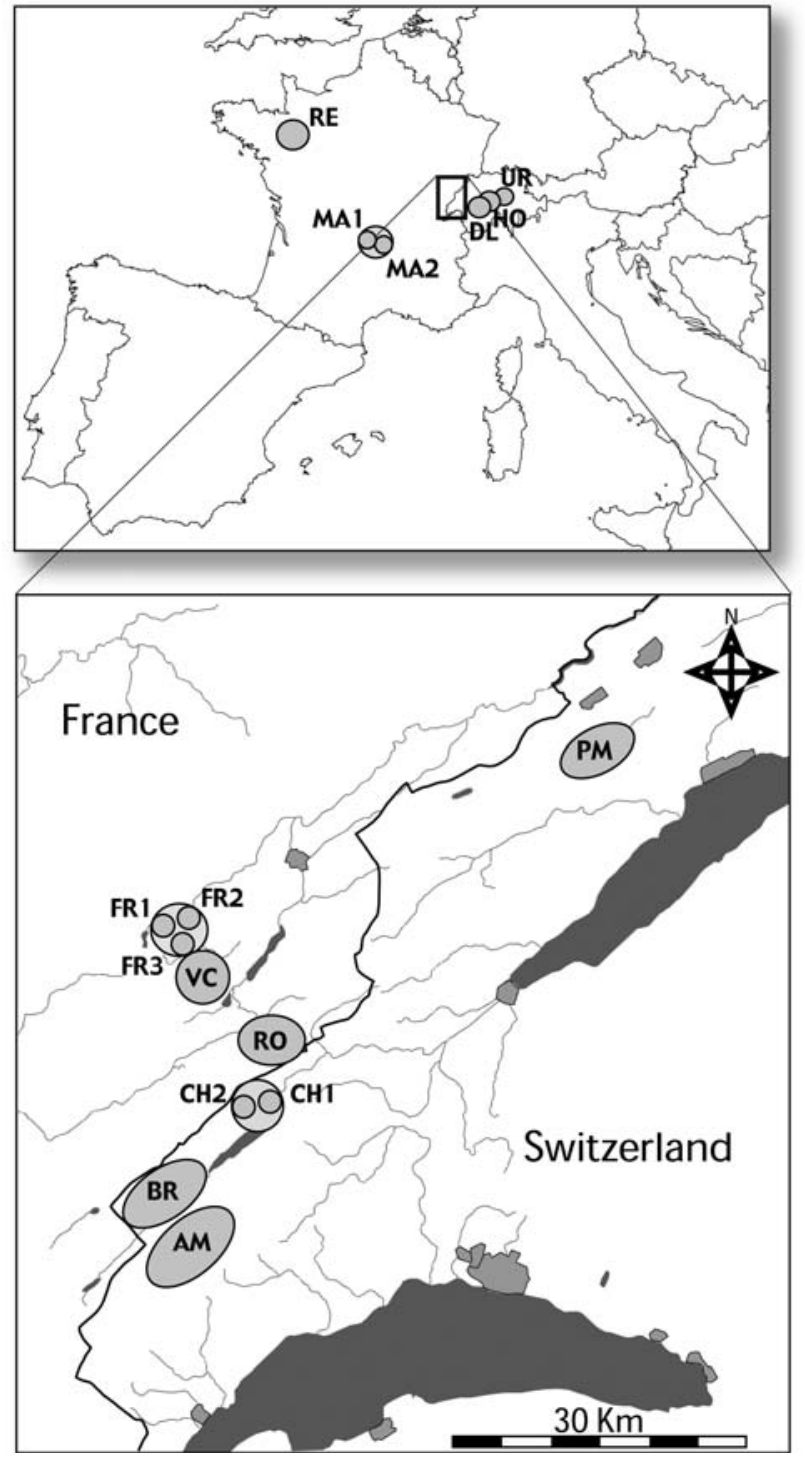

Fig. 1 Distribution of the sampled populations of Vipera berus. Population codes correspond to Table 2. Population groups CH1-2, FR1-3, and MA1-2 contain geographically close $(<3.5 \mathrm{~km})$ subpopulations

samples were taken (blood or scales). Genomic DNA was extracted using the QIAamp DNA Mini Kit (Qiagen).

Microsatellite development

Microsatellite enriched-libraries of adder were obtained from GIS (Genetic Identification Services, Chatsworth, US). DNA fragments containing (CA), (GA), (AAC) and (AAG) repeats were cloned with One Shot ${ }^{\circledR}$ Top10 cells (Invitrogen AG, Basel, Switzerland). Plasmids of 102 positives colonies were amplified using primers M13f and M13r (Invitrogen). PCR products were checked on agarose gels, then purified using the QIAquick PCR Purification Kit (Qiagen) and sequenced. Primers for sequences containing microsatellites were designed using OLIGo V 4.0 (Molecular Biology Insights, Inc., Cascade, US). Microsatellite amplifications were checked on agarose gels and PCR conditions were optimised for each locus.

Microsatellite amplification

PCR amplifications were conducted in $25 \mu \mathrm{l}$ volumes with $2 \mu \mathrm{l}$ of DNA template, $1 \times$ PCR buffer (Qiagen), $2 \mathrm{mg} / \mathrm{ml}$ of $\mathrm{Q}$ solution (Qiagen), $\mathrm{MgCl}_{2}$ concentration according to the locus amplified (see Table 1), $0.2 \mathrm{mM}$ dNTPs, $0.5 \mu \mathrm{M}$ of each primer and 0.5 units of Taq polymerase (Qiagen); forward primers were labelled with fluorescent dye. Amplification of microsatellite loci was carried out in PE9700 thermo-cyclers (Applied-Biosystems) under various annealing temperatures (see Table 1). All reactions consisted of 35 cycles of $30 \mathrm{~s}$ at $94^{\circ} \mathrm{C}, 30 \mathrm{~s}$ at annealing temperature (Table 1) and $45 \mathrm{~s}$ at $72^{\circ} \mathrm{C}$, followed by a final 5 min extension at $72^{\circ} \mathrm{C}$. Microsatellite PCR products were run on an ABI 377 automated sequencer and allele sizes were scored using the program GenSCAN 3.1 (Applied Biosystems).

\section{Mitochondrial DNA amplification and analyses}

Additionally, a portion of the mitochondrial DNA (mtDNA) cytochrome b gene (cyt. b) has been sequenced accordingly to Ursenbacher et al. (2006) in one population of the four main studied areas (Jura Mountains, Alps, Central and Western France), in order to evaluate mitochondrial genetic diversity. Ten samples from each population (FR1, UR, MA1 and RE) were randomly selected. Genetic diversity was estimated using Mega 3.1 (Kumar et al. 2004) and statistical parsimony (with TCS v1.21; Clement et al. 2000) was used to infer relationship between haplotypes. To test for evidence of population growth from low-diversity founder populations, we performed a Fu's $F_{S}(F u$ 1997) test in order to test for an excess of rare alleles, and pairwise mismatch distributions among all individuals were plotted and tested for goodnessof-fit (both with ARLEQuin 3.0; Excoffier et al. 2005).

Statistical analysis of microsatellites

Loci were examined for null alleles and mis-scoring with Micro-CHEKer 2.1 (Van Oosterhout et al. 2004) for each population. Loci showing a high probability $(\mathrm{P}>0.05)$ of null alleles were discarded from the dataset. For each retained locus, we estimated allele frequency, allelic richness $\left(\mathrm{A}_{\mathrm{R}}\right)$, observed and expected heterozygosity $\left(\mathrm{H}_{\mathrm{O}}, \mathrm{H}_{\mathrm{E}}\right)$ using Fstat 2.9.3 (Goudet 1995). The heterozygote deficit within populations $\left(\mathrm{F}_{\mathrm{IS}}\right)$ was calculated and divergence from Hardy-Weinberg equilibrium was tested using FstaT 


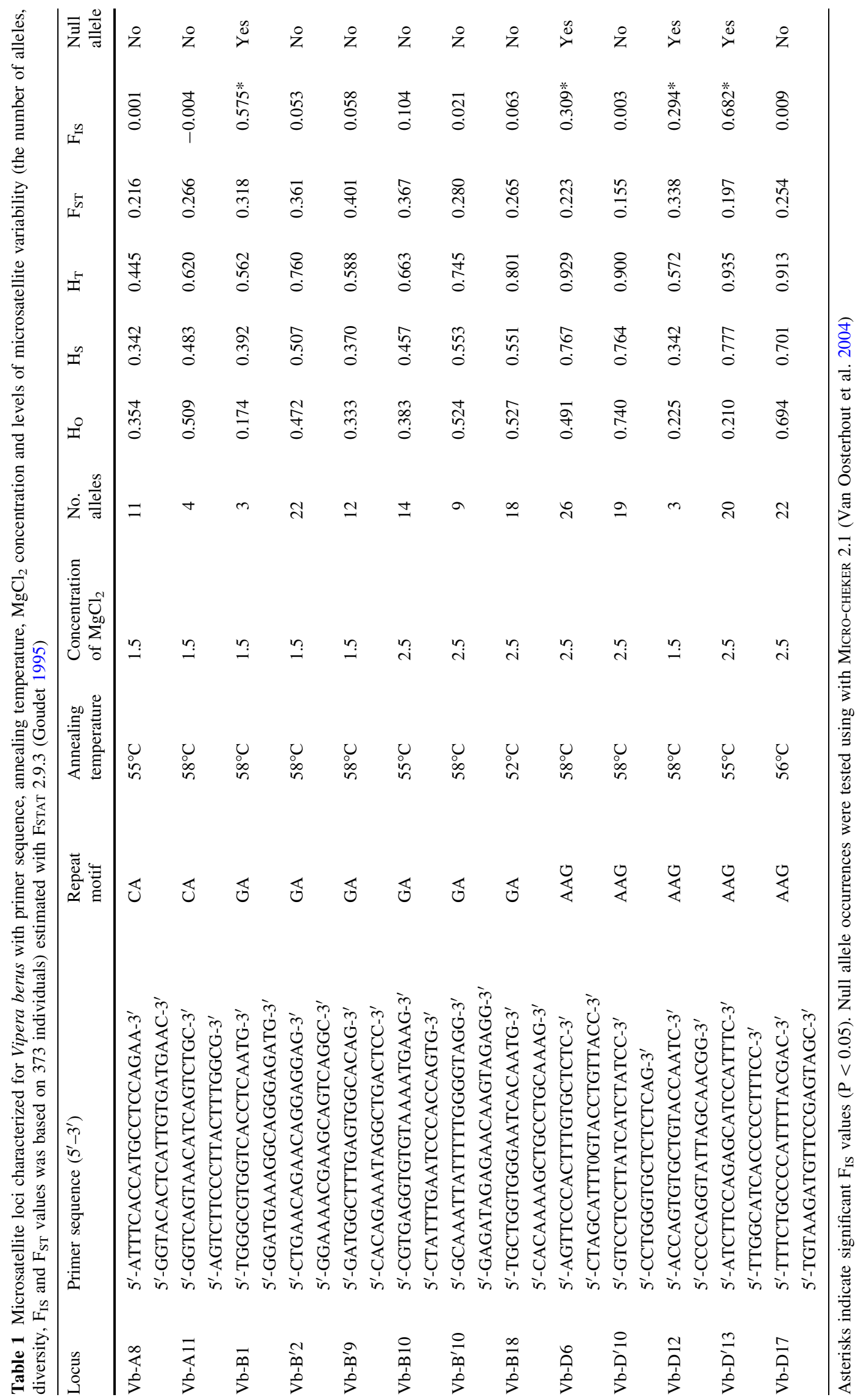


with 1,000 permutations. Moreover, linkage between loci was also tested with FsTAT.

We compared allelic richness and gene diversity among groups of populations (Jura Mountains, Alps and Massif Central) with an ANOVA using SPSS 11.1 (SPSS Inc., Chicago, US).

\section{Bottleneck estimation}

To test whether bottlenecks could be inferred from our allele frequency data, we used the program BotTLENECK (Cornuet and Luikart 1996; Piry et al. 1999). When running BotTLENECK simulations, the two-phase model (TPM; di Rienzo et al. 1994) with parameters set to $95 \%$ of singlestep mutation (SSM; Ohta and Kimura 1973) and a variance among multiple steps equal to 12 was chosen as suggested in Piry et al. (1999). To assess the robustness of these tests, additional simulations with different parameters values (80-99\% of SSM, 2-24 of variance among multiple steps) were performed. Based on the number of loci used, Wilcoxon tests were performed for the statistical analysis of heterozygote excess.

Estimations of the population size $(\mathrm{N})$ and the effective population size $\left(\mathrm{N}_{\mathrm{E}}\right)$

When more than four sessions of capture have been conducted in the population, the adult population size $(\mathrm{N})$ was estimated using the module CAPTURE (Otis et al. 1978) implemented in the software MARK 3.2 (Marshall et al. 1998). This method can be used for close populations (no migration, death or recruitment) and allows variable catchability between animals or between time. This approach is particularly appropriate to estimate European viper populations (see e.g. Bonnet and Naulleau 1996; Ursenbacher and Monney 2003). Moreover, the effective population size $\left(\mathrm{N}_{\mathrm{E}}\right)$ was calculated via two different methodologies: the first approach infers effective population size from linkage disequilibrium using the calculation suggested by Bartley et al. (1992) and implemented in NeEstimator (Peel et al. 2004). The second method uses more than one-locus genetic data to estimate the effective size of the population and is expected to give reliable evaluations also for small populations and with a limited number of microsatellite loci (Vitalis and Couvet 2001a). The calculation was conducted with the software Esтiм 1.2. (Vitalis and Couvet 2001a). Results of both methods are compared.

Genetic differentiation between populations

Genetic differentiation between populations, $\mathrm{F}_{\mathrm{ST}}$ (Weir and Cockerham 1984), was calculated and tested for significant departure from zero by permutation (1,000 replicates) of individual genotypes between samples using FSTAT, without assuming Hardy-Weinberg equilibrium. For analyses involving multiple comparisons, the critical probability for each test was adjusted using the sequential Bonferroni correction (Rice 1989).

In addition, we performed a spatial autocorrelation analysis using SPAGEDi (Hardy and Vekemans 2002) in order to determine correlation between geographic distances and genetic relatedness measured by Moran's I-statistic (Moran 1950; Sokal and Wartenberg 1983; Hardy and Vekemans 1999). Distance classes were chosen in order to have similar numbers of pairwise comparisons and allowing regression of relatedness against log distance over reasonable distances for populations. Ninety five percent confidence intervals were calculated by bootstrapping 10,000 times within each distance class.

Isolation by distance for the Jura Mountain populations was tested using Mantel's test (Mantel 1967) by comparing pairwise $\left(\mathrm{F}_{\mathrm{ST}} /\left(1-\mathrm{F}_{\mathrm{ST}}\right)\right)$ values with pairwise geographic distances (log transformed) using the program FSTAT. This transformation has been showed to be more accurate to test for isolation by distance than $\mathrm{F}_{\mathrm{ST}}$ versus geographic distance (Rousset 1997).

Monmonier's maximum-difference algorithm (Monmonier 1973) implemented in the software BARRIER 2.2 (Manni et al. 2004) was used to identify putative geographical boundaries (i.e. barriers) resulting from pronounced genetic discontinuities among samples. For this analysis, a Delaunay triangulation network (Brassel and Reif 1979), is constructed in order to connect adjacent populations. Pairwise population genetic differentiation is then coupled to each linked population pair and the Monmonier maximum difference algorithm (Monmonier 1973) is used to determine genetic delimitations. To ensure that barriers were not determined by strong differentiation at only one or few loci, $\mathrm{F}_{\mathrm{ST}}$ values for each microsatellite marker separately and the $\mathrm{F}_{\mathrm{ST}}$ value regrouping all loci were calculated and used to define consensus barriers (determined by a majority rule and indicating how many loci support a given section of the barrier).

\section{Results}

Null alleles and Hardy-Weinberg equilibrium

We optimised 13 loci with variable levels of polymorphism (see Table 1). Tests for Hardy-Weinberg equilibrium showed that four of them (Vb-B1, Vb-D6, Vb-D12 and $\mathrm{Vb}-\mathrm{D}^{\prime} 13$ ) were characterized by a significant excess of homozygotes $(\mathrm{P}<0.05)$. Moreover only these four loci presented excess of homozygotes for several populations 
when checked with Micro-CHEKER. In addition, locus Vb-D17 was linked with Vb-B18 and Vb-B' 10 , as well as $\mathrm{Vb}^{\prime} \mathrm{B}^{\prime} 9$ with $\mathrm{Vb}-\mathrm{D}^{\prime} 10(\mathrm{P}<0.05)$. Consequently, we only considered the following seven loci for further analyses: Vb-A8, Vb-A11, Vb-B'2, Vb-B10, Vb-B'10, Vb-B18 and $\mathrm{Vb}-\mathrm{D}^{\prime} 10$.

Moreover, high homozygosity for $\mathrm{Vb}-\mathrm{B}^{\prime} 10$ within population MA1 and for Vb-B10 within population RE was detected, possibly due to null alleles within the respective populations. Without the problematic primers, $\mathrm{F}_{\mathrm{IS}}$ values

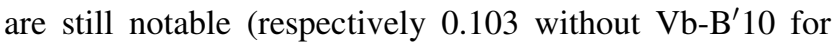
population MA1 and 0.125 without $\mathrm{Vb}-\mathrm{B} 10$ for population RE) but not significant.

\section{Mitochondrial analysis}

Five different haplotypes (GenBank numbers: EU585845EU585849) were detected in a $764 \mathrm{bp}$ portion of the mtDNA cyt. b (see Fig. 2). The ancestral haplotype suggested by TCS analysis was the haplotype most frequently observed in MA1 populations. A unique haplotye was detected in FR1 and RE populations, whereas two different haplotypes have been detected in MA1 and UR. Consequently, the genetic diversity was higher in these two populations. No signal of recent expansion has been detected by Fu's $\mathrm{F}_{\mathrm{S}}$ test $\left(\mathrm{F}_{\mathrm{S}}=0.54 ; \mathrm{P}=0.66\right)$ or mismatch distribution (goodness-of-fit test: $\mathrm{P}=0.005$ ).

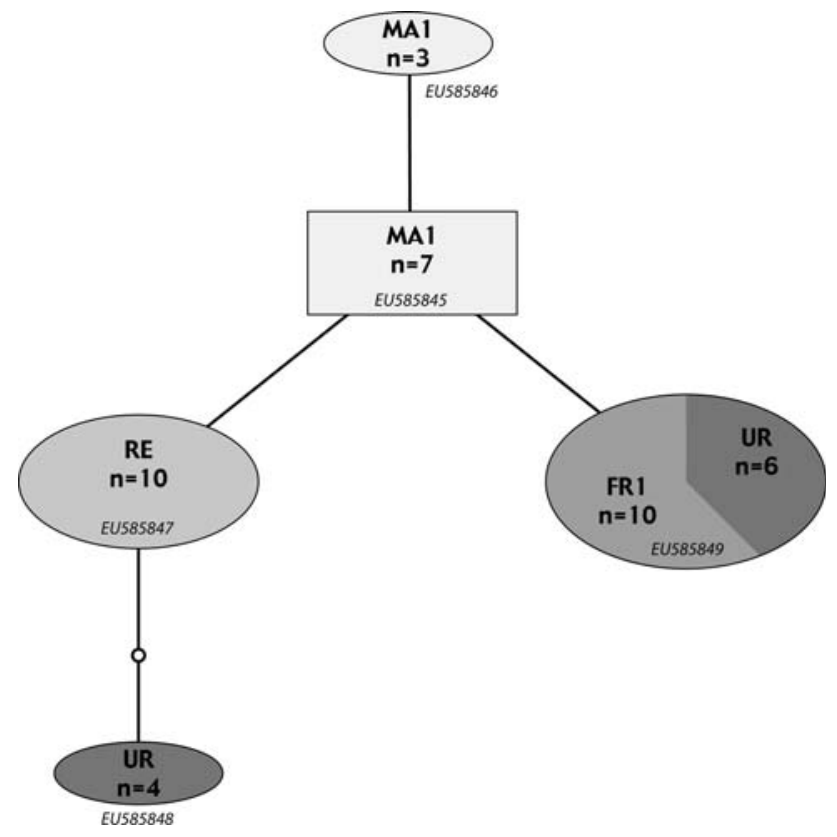

Fig. 2 Statistical parsimony network (obtained with TCS; Clement et al. 2000) of a portion of the cytochrome b (764 bp) sequenced in four populations (MA1, RE, FR1 and UR). GenBank numbers of the five different haplotypes are indicated. $\mathrm{N}$ corresponds to the number of samples sharing the same haplotype
Microsatellite analysis

Genetic variability, expressed as the mean allelic richness $\left(A_{R}\right)$ and the expected heterozygosity $\left(H_{E}\right)$, was significantly lower in the Jura Mountains and in the Alps than in the Massif Central and the Rennes regions $\left(A_{R}\right.$ : ANOVA, $\mathrm{F}=8.81, \mathrm{P}=0.002 ; \mathrm{H}_{\mathrm{E}}: \mathrm{ANOVA}=6.35, \mathrm{P}=0.008 ;$ see Table 2).

Two populations (MA1 and RE) showed significant $(\mathrm{P}<0.05)$ sub-structure $\left(\mathrm{F}_{\mathrm{IS}}\right)$, mainly due to the high homozygosity of a single locus (see above). All other populations did not display any significant sub-structure (Table 2).

The Wilcoxon's sign-rank test implemented in BOTTLENECK detected a significant excess of heterozygotes only in the $\mathrm{DL}$ population $(\mathrm{P}=0.016)$. Moreover, this population presented an $A_{R}$ significantly lower than the other populations in the Jura Mountains $(\mathrm{t}=2.399$, $\mathrm{P}=0.043)$.

Population size $(\mathrm{N})$ and effective population size $\left(\mathrm{N}_{\mathrm{E}}\right)$

The adult population size and the effective population size calculated using two different approaches were estimated for the majority of the populations (see Table 2). Six locations were estimated to have an infinite effective population size, due to a negative $\eta_{\mathrm{s}}$ (the "within-subpopulation identity disequilibrium" which describes the extent to which gene identities are correlated across loci, see Vitalis and Couvet 2001b; Table 2) with the Estim approach, whereas two have comparable problems with NeEstimATOR. No relationship was detected between the effective population size $\left(\mathrm{N}_{\mathrm{E}}\right)$, after removing the infinite values, and the population size estimated by capture-recapture (respectively for EsTiM: $\mathrm{r}^{2}=0.003, \mathrm{P}=0.930$; and for NeEstimator: $\mathrm{r}^{2}=0.005$, $\mathrm{P}=0.893$ ) or the allelic richness (respectively $\mathrm{r}^{2}=0.039$, $\left.\mathrm{P}=0.583 ; \mathrm{r}^{2}=0.045, \mathrm{P}=0.466\right)$, as well as between the adult population size and the allelic richness $\left(\mathrm{r}^{2}=0.139\right.$, $\mathrm{P}=0.410$ ). Moreover, no relationship between effective population size estimations from both different methods was observed $\left(\mathrm{r}^{2}=0.004, \mathrm{P}=0.872\right)$.

Population differentiation

Overall, we found a high and significant genetic differentiation between populations (mean $\mathrm{F}_{\mathrm{ST}}=0.269, \mathrm{P}<$ 0.001; see Table 3; mean $\mathrm{F}_{\mathrm{ST}}=0.236, \mathrm{P}<0.001$ for Jura mountains populations only). For populations less than $3.5 \mathrm{~km}$ apart (population groups), the $\mathrm{F}_{\mathrm{ST}}$ values were lower, but were still noticeable (between 2.6 and 6.9\%) and sometimes significant. Moreover, some populations (DL, and to a lesser extent AM and PM) showed high pairwise $\mathrm{F}_{\mathrm{ST}}$ values. Finally, a strong isolation by distance was 
Table 2 Genetic diversity for 16 Vipera berus populations based on seven microsatellites

\begin{tabular}{|c|c|c|c|c|c|c|c|c|c|}
\hline & Populations & $\mathrm{n}$ & $\mathrm{H}_{\mathrm{O}}$ & $\mathrm{H}_{\mathrm{E}}$ & $A_{R}$ & $\mathrm{~F}_{\mathrm{IS}}$ & $\mathrm{N}$ & $\mathrm{N}_{\mathrm{E}}$ EsTim & $\mathrm{N}_{\mathrm{E}}$ NeEstimator \\
\hline \multirow[t]{20}{*}{ Jura Mountains } & $\mathrm{CH} 1$ & 63 & 0.533 & 0.533 & 3.14 & -0.003 & $46 \pm 10$ & 132.20 & 39.3 \\
\hline & & & & & & & & & $28.3-58.1$ \\
\hline & $\mathrm{CH} 2$ & 62 & 0.511 & 0.515 & 2.94 & 0.005 & $31 \pm 6$ & 52.46 & 37.1 \\
\hline & & & & & & & & & $25.2-59.5$ \\
\hline & BR & 34 & 0.56 & 0.589 & 3.14 & 0.042 & $20 \pm 4$ & 144.04 & 63.4 \\
\hline & & & & & & & & & $29.9-597.5$ \\
\hline & PM & 30 & 0.351 & 0.387 & 2.19 & 0.044 & $20 \pm 8$ & $\infty$ & 17.6 \\
\hline & & & & & & & & & $9.9-39.5$ \\
\hline & $\mathrm{AM}$ & 24 & 0.382 & 0.439 & 2.81 & 0.096 & $20 \pm 10$ & 210.80 & $\infty$ \\
\hline & & & & & & & & & $37.3-\infty$ \\
\hline & RO & 14 & 0.52 & 0.478 & 2.32 & -0.09 & & 7.16 & 7.1 \\
\hline & & & & & & & & & $4.0-15.2$ \\
\hline & $\mathrm{VC}$ & 12 & 0.476 & 0.458 & 2.58 & -0.039 & & 62.60 & 14.4 \\
\hline & & & & & & & & & $6.7-89.9$ \\
\hline & FR1 & 17 & 0.518 & 0.516 & 2.97 & -0.005 & & $\infty$ & $\infty$ \\
\hline & & & & & & & & & $34.6-\infty$ \\
\hline & FR2 & 14 & 0.527 & 0.502 & 2.95 & -0.038 & $17 \pm 8$ & 14.40 & 4.1 \\
\hline & & & & & & & & & $2.8-6.3$ \\
\hline & FR3 & 15 & 0.495 & 0.512 & 2.86 & 0.034 & $15 \pm 7$ & $\infty$ & 76.3 \\
\hline & & & & & & & & & $16.3-\infty$ \\
\hline \multirow[t]{6}{*}{ Alps } & UR & 20 & 0.457 & 0.47 & 2.91 & 0.027 & & 144.31 & 11.7 \\
\hline & & & & & & & & & $6.7-24.8$ \\
\hline & $\mathrm{HO}$ & 23 & 0.638 & 0.589 & 3 & -0.086 & & $\infty$ & 76.0 \\
\hline & & & & & & & & & $24.8-\infty$ \\
\hline & DL & 22 & 0.347 & 0.376 & 2.11 & 0.075 & & 24.16 & 106.7 \\
\hline & & & & & & & & & $18.0-\infty$ \\
\hline \multirow[t]{4}{*}{ Massif Central } & MA1 & 18 & 0.556 & 0.681 & 4.04 & $0.184 *$ & & $\infty$ & 27.8 \\
\hline & & & & & & & & & $16.4-67.2$ \\
\hline & MA2 & 5 & 0.629 & 0.679 & 3.86 & 0.074 & & $\infty$ & 5.3 \\
\hline & & & & & & & & & $3.0-12.8$ \\
\hline \multirow[t]{2}{*}{ Rennes } & $\mathrm{RE}$ & 19 & 0.501 & 0.6503 & 3.8 & $0.256^{*}$ & & 28.89 & 35.0 \\
\hline & & & & & & & & & $16.6-424.8$ \\
\hline
\end{tabular}

$\mathrm{n}=$ sample size $\mathrm{H}_{\mathrm{O}}=$ observed heterozygosity; $\mathrm{H}_{\mathrm{E}}=$ expected heterozygosity, $\mathrm{A}_{\mathrm{R}}=$ allelic richness (based on three diploid individuals); $\mathrm{F}_{\mathrm{IS}}=$ heterozygote deficit within populations (asterisks indicate significant values with $\mathrm{P}<0.05$ ); $\mathrm{N}=$ estimated population size (adults only) based on capture-mark-recapture methods; $\mathrm{N}_{\mathrm{E}}=$ effective population size estimated by Estim (Vitalis and Couvet 2001a)

detected within the Jura Mountains populations (Mantel test P-value <0.01; see Fig. 3).

Spatial autocorrelation analyses also suggested a strong relationship between the distance and the relatedness measured as Moran's Indices. Indeed, for a distance lower than about $3 \mathrm{~km}$, relatedness deviated significantly from zero ( $\mathrm{P}<0.05$; see Fig. 4$)$.

Geographic structure between Jura Mountains populations

BARRIER is not designed to identify the optimal number of barriers, consequently this number must be set by the user.
With our data, one or two barriers seem to be the optimum. Major barriers can be highlighted between population PM and all other populations (PM population showed the highest mean $\mathrm{F}_{\mathrm{ST}}$ value of the Jura Mountains populations). However, this population is geographically the most isolated and isolation by distance is the probable reason for the determination of this barrier. The analysis using BARRIER, however showed the presence of a genetic discontinuity between populations FR1 + FR2 + FR3 + $\mathrm{VC}$ and populations $\mathrm{CH} 1+\mathrm{CH} 2+\mathrm{RO}+\mathrm{BR}+\mathrm{AM}$ (Fig. 5). Isolation by distance is probably not the main reason for this split, because populations $\mathrm{CH} 1$ or $\mathrm{CH} 2$ are at a similar distance from BR than from FR1, FR2 or FR3. 


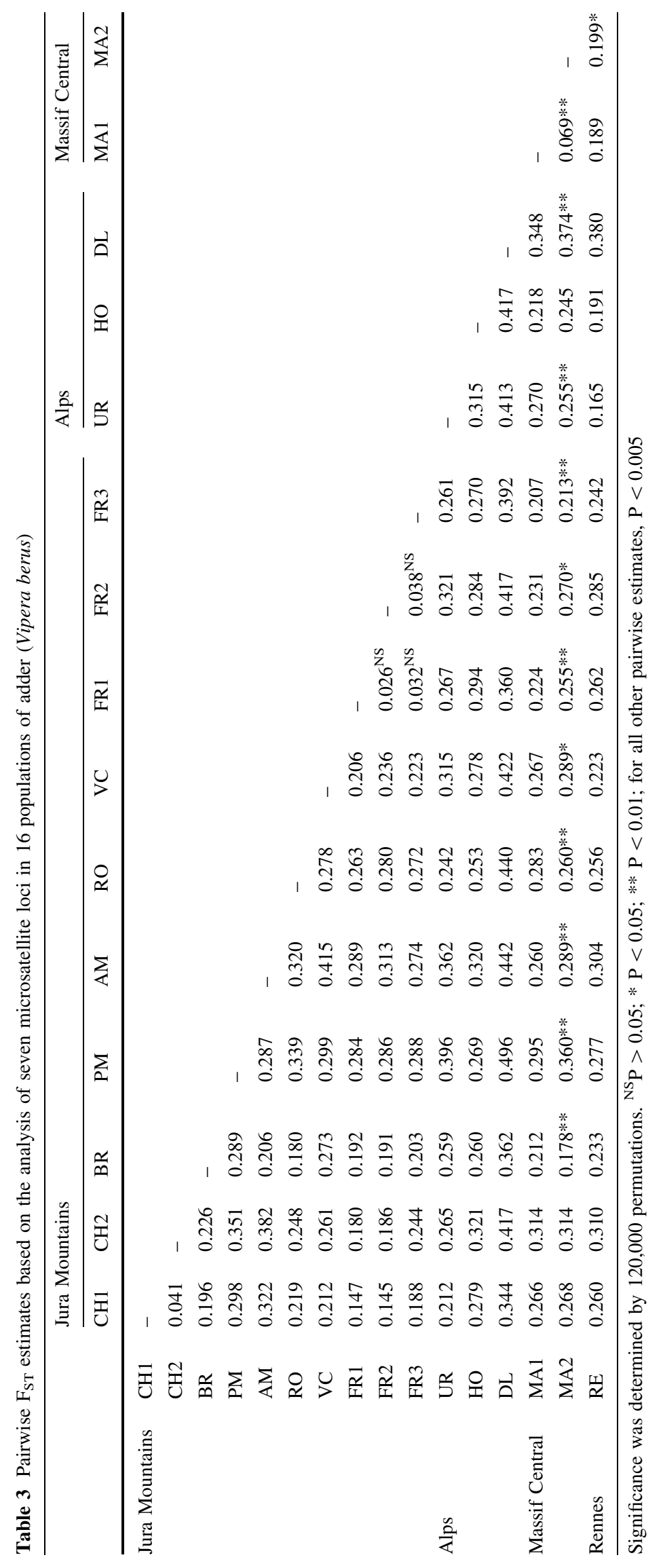




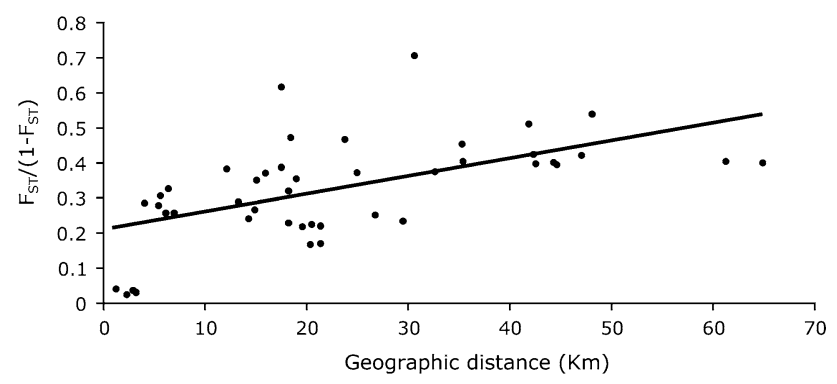

Fig. 3 Isolation by distance in ten Jura Mountains populations of Vipera berus $\left(\mathrm{r}^{2}=0.33, \mathrm{P}<0.01\right)$. Comparisons are pairwise between all populations

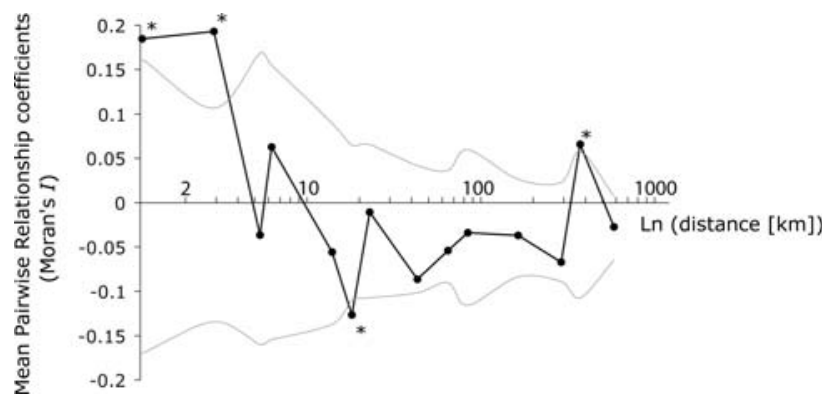

Fig. 4 Spatial autocorrelogram for the Jura Mountains populations. Grey lines correspond to $95 \%$ confidence interval determined by SPAGEDi (Hardy and Vekemans 2002). *Correspond to significant values

\section{Discussion}

Genetic diversity within and among the studied regions

Based on microsatellite allelic variation and heterozygosity, we found the genetic diversity within the Jura Mountains and the Alps to be significantly lower than in the Massif Central and the Atlantic coast (Rennes) populations. Three hypotheses can be suggested to explain these results. First, bottleneck events are often associated with substantial reductions of genetic diversity (see e.g. Hartl and Clark 1997). In our case however, no bottlenecks were detected in most of the studied populations. Second, small population size also has a negative impact on the genetic diversity retained in fragmented populations due to drift (Frankham 1995). The alpine populations are, however, only marginally affected by anthropogenic activities and their environment is generally less disturbed. Consequently, population sizes and $\mathrm{N}_{\mathrm{E}}$ are comparable in the Alps, the Massif Central and the Atlantic coast. Furthermore, we did not find a significant relationship between $\mathrm{N}_{\mathrm{E}}$ and $A_{R}$ in our data. Lastly, reduced genetic diversity could be related to historical events, such as recolonisation patterns after glacial periods (Hewitt 1999). Indeed, the

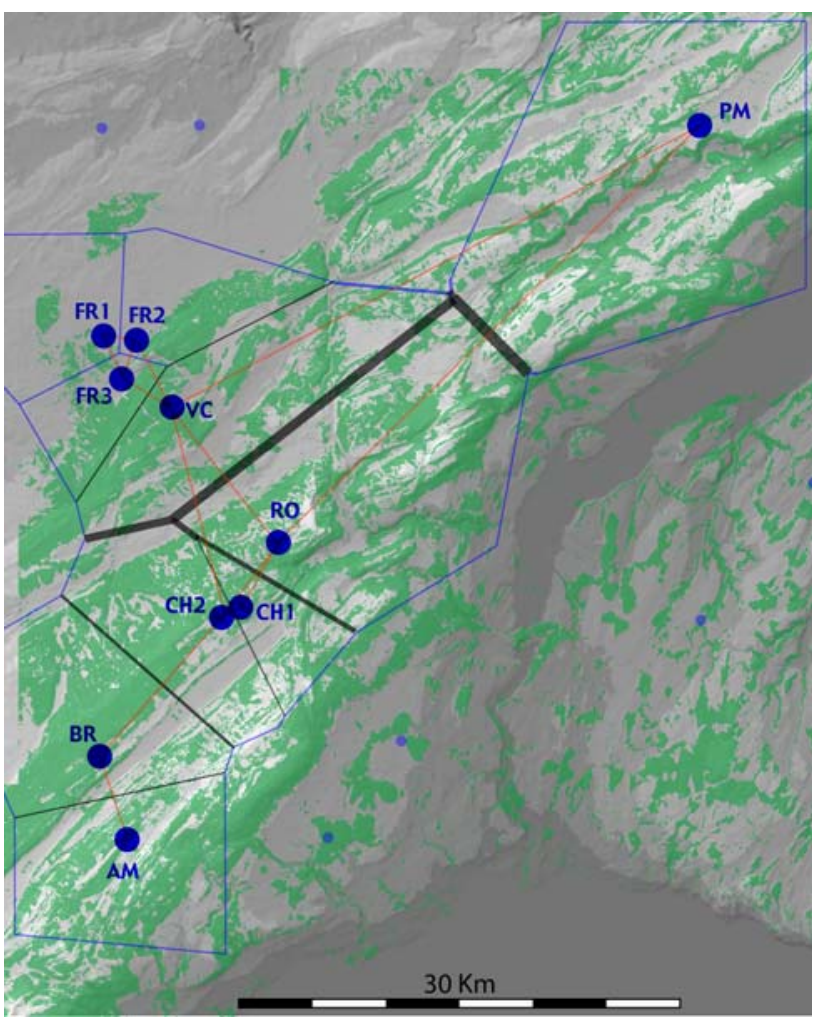

Fig. 5 Barrier locations between sampled populations estimated by BARRIER (Manni et al. 2004), where thickness is proportional to divergence between populations. Blue lines correspond to the Voronoï tessellation whereas green patches correspond to forest area and grey scale to altitude. To avoid divulging the exact location of remnant populations, the network resulting from the BARRIER analysis has been slightly shifted. Populations correspond to map in Fig. 1

decline in genetic polymorphism appears to be positively related to the geographical distance from the presumed glacial refugia for $V$. berus. Thus, we suggest that the lower genetic variability observed in the Alps and the Jura Mountains originate from the larger distance between these areas and the adder's glacial refugia in southern France (see Ursenbacher et al. 2006). However, mitochondrial analyses only partially support this hypothesis. The central position in the network of the haplotypes from Massif Central population, as well as the higher genetic diversity observed in this region (compared to Rennes and Jura Mountains regions), confirm this hypothesis. On the opposite, the presence of a similar number of haplotypes (2) in UR population (Alps region) and in Massif Central (MA1), as well as the lack of detection of a sudden population expansion (measured with mismatch distribution analyses) do not support the hypothesis of a reduction of genetic diversity in the easternmost studied regions due to post-glacial recolonisation. Consequently, additional sampling at comparable distances from these putative 
glacial refugial areas (for example in north-eastern France) should be performed in order to confirm this hypothesis.

Genetic diversity within the Jura Mountains and the Alps

Although the genetic diversity within the populations of the Jura Mountains and Alps is low, possibly due to historical events, two populations (PM and DL) had a particularly low genetic variability, especially DL where our bottleneck analysis indicated a strong effect of historical isolation. BoTTLENECK software can detect severe reductions of population size within a temporal range of $2 \mathrm{~N}_{\mathrm{E}}-4 \mathrm{~N}_{\mathrm{E}}$ generations (Piry et al. 1999), thus the detection range can be evaluated from 240 to 1,600 years for the adder (with a generation time of 6-8 years for adders in mountains and $\mathrm{N}_{\mathrm{E}}$ between 20 and 50). Consequently, the detected bottleneck predated human persecutions and was probably the result of a recent colonisation of this area. The high $\mathrm{F}_{\mathrm{ST}}$ values between this and other populations also suggested a recent colonisation by a low number of founder individuals followed by genetic drift.

Within the PM population, no bottleneck was detected although the population displayed a low $A_{R}$ value. Referring to old data (Ischer 1930), a severe decrease in the number of killed adders in the district council of the PM population (227 were killed between 1906 and 1909, whereas only 19 were killed between 1926 and 1929) was reported, but this reduction is too recent (about 15 generations) to be detected by BotTLeneck. Populations located in the last main population group of $V$. berus in the Jura Mountains (FR1, FR2 and FR3) did not show higher diversity values than other small and isolated populations in this region ( $t$-test $=-0.855, \mathrm{P}=0.417$ ), and $\mathrm{A}_{\mathrm{R}}$ estimates in the bigger populations in the Alps and in the Jura Mountains (except DL see above) are comparable. Therefore, it seems that most studied populations of adders in the Jura Mountains did not already suffer from a severe depauperation of their genetic variability, on the opposite for instance of an isolated Swedish population studied by Madsen et al. (1996) which showed evidence of inbreeding depression due to small population size. However, shortterm risks from both demographic and genetic stochasticity could lead to extinction without appropriate management (see below).

\section{Geographic structure}

The highest mean $\mathrm{F}_{\mathrm{ST}}$ value as well as the results from BARRIER analysis suggested an isolated position of the PM population (Val de Travers), probably due to the high distance, as well as lower altitudinal range, which is not favourable to $V$. berus. Isolation by distance is detectable in our dataset, and a pronounced isolation occurs between two groups of populations, respectively FR1, FR2, FR3 and $\mathrm{VC}$ and $\mathrm{RO}, \mathrm{CH} 1, \mathrm{CH} 2, \mathrm{BR}$ and AM (Fig. 5), corresponding to the main regions of occurrence of the species' remnant populations, Bassin du Drugeon and the MontRisoux/Mont d'Or/Vallée de Joux respectively. The split between these two groups is probably not determined only by distance, because geographic distances between $\mathrm{CH} 1$ and BR or FR1 are similar, whereas a barrier was found between the second pair. The reason for the split may be due to an open, deforested and a lower altitude area (high basin of the Doubs), which is relatively unfavourable for this species. In addition, both groups belong to different river basins, which could also have had an impact on the recent post-glacial colonisation. However, intermediate samples should be analysed to confirm this split, but the number of adders located between these two groups is very limited. From a conservation aspect, the presence of two groups located each side of the high basin of the Doubs river is important if translocations are intended.

Population differentiation and high phylopatry within Viperidae

The genetic differentiation among $V$. berus populations appears to be large, even for populations at a local scale. Including all sets of isolated populations (geographical distances $\geq 3.5 \mathrm{~km}$ ), pairwise $\mathrm{F}_{\mathrm{ST}}$ values were higher than 0.14 . In addition, spatial autocorrelation analysis confirmed the difference observed between populations separated by less or more than 3-4 km. Populations separated by less than $3 \mathrm{~km}$ of suitable habitat $(\mathrm{CH} 1$ and $\mathrm{CH} 2$; FR1, FR2 and FR3; MA1 and MA2) had limited $\mathrm{F}_{\mathrm{ST}}$ values (between 2.6 and $6.9 \%$ ). Nevertheless, the genetic differentiation is significant between populations with larger sample $(\geq 20$ individuals). Therefore, genetic differentiation within $V$. berus population groups appears to be extensive even when the environment does not a priori preclude dispersal between populations. This result suggests that migration between close populations is limited in adders, and confirms the phylopatric behaviour of the species already suggested by Madsen and Shine (1992) and Luiselli (1993). More generally, this observation also supports the low migration potential within Viperidae as already observed in Sistrurus catenatus and Crotalus horridus (Villarreal et al. 1996; Gibbs et al. 1997). The $\mathrm{F}_{\mathrm{ST}}$ value (0.04) between populations of Sistrurus $1.5 \mathrm{~km}$ apart was comparable to the values observed among $V$. berus populations at a similar distance. Analogous values of $\mathrm{F}_{\mathrm{ST}}$ have also been observed for $C$. horridus between hibernacula areas separated by $0.5-3 \mathrm{~km}\left(\mathrm{~F}_{\mathrm{ST}}\right.$ values: $\left.0.05-0.12\right)$. Overall, these observations confirm the high phylopatric behaviour of temperate Viperidae species (but see Jäggi et al. 2000), 
contrasting with the observations conducted on temperate Colubridae (see Lougheed et al. 1999; Prosser et al. 1999).

Implications for conservation

In addition to protecting habitat, understanding the population genetic structure and the extent of gene flow is essential for the management of small and isolated populations (see e.g. Frankham et al. 2002). Our results showed that genetic population differentiation in adders is substantial even at small geographic scales, possibly due to phylopatric behaviour. Consequently, all populations separated by more than $3 \mathrm{~km}$ should be considered as relatively isolated, and closer populations, which displayed significant genetic structuring, should also be considered as distinct units. Subsequently, all remnant adder populations, even if they seem geographically inter-connected, must be treated as separated management units in order to preserve the maximum amount of genetic variability. These results, together with the small area occupied by each of them (most of the remnant populations survive in a suitable habitat limited to 15-30 ha) and the low number of adults (most comprised by less than 50 adults) suggest several management strategies for $V$. berus in the Jura Mountains (and possibly also for other fragmented adders populations).

First, all remnant populations retain a particular genetic composition due to their isolation. Consequently, they all play a major role in maintaining the genetic diversity of this species in the Jura Mountains: therefore, protection efforts must not focus solely on large and inter-connected populations.

Second, since migration between populations appears limited, the establishment of corridors connecting current populations, and the creation of new favourable sites located more than $2-3 \mathrm{~km}$ apart from remnant populations, would probably be ineffective. In order to increase the area occupied by the species, we suggest that the habitat quality directly surrounding $(<1 \mathrm{~km})$ the current populations should be improved, allowing individuals to gradually colonise new sites. However, it should be noted that a progressive spread in the surroundings could only be achieved if the demography of the central population is positive. In addition, the quality of the remnant suitable habitats should be improved, in particular concerning food availability. The increase in the density of the common lizard (Zootoca vivipara) and the common frog (Rana temporaria), both major prey species of adder juveniles, should raise survival rate and, consequently, enhance emigration due to a growth in density. Thus, the creation of new wetlands, ponds and areas with small, differentiated structures should be suitable for the species' conservation.
In conclusion, the major investments for $V$. berus protection should be focused on the remnant, threatened populations in order to minimize losses of genetic diversity and to allow potential colonisation of suitable surrounding areas. Presently, the genetic results did not indicate strong bottlenecks or severe reduction of genetic diversity in Jura Mountains populations, as Madsen et al. (1996) found in Smygehuk (Sweden). In the latter, translocations of males was used to re-establish a viable population (Madsen et al. 1999; Madsen et al. 2004). The appropriateness of translocations in the Jura Mountains, in order to prevent deleterious genetic consequences in isolated fragments, is not obvious and could lead to other major concerns such as disease transmission or outbreeding depression (even if outbreeding depression is very unlikely to occur between individuals from proximate populations and living in similar habitat). In addition, before making decisions about any potential translocation plan, indirect estimates of individual fitness, such as neonatal survival rate (Madsen et al. 1996) or the occurrence of developmental anomalies (see Gautschi et al. 2002; Ujvari et al. 2002), should be performed in order to detect potential signs of inbreeding depression.

Acknowledgments This work was funded by grants from the Swiss National Foundation (Grant Number 3100-059132.99/1 and Fellowship for prospective researchers) and the Société Académique Vaudoise. We acknowledge T. Durand, F. Paysant and G. Thiery for the sampling. Samples were taken with the permission of la Conservation de la Faune du Canton de Vaud (Switzerland), le Service de la Faune from Neuchâtel and Fribourg (Switzerland), the Préfecture du Département du Doubs (France) and the Préfecture du Département du Jura (France). Discussions with J. Goudet, J. Parker, C. E. Pook, P. Taberlet and J. Yearsley, and comments from two anonymous reviewers, greatly improved the manuscript.

\section{References}

Allendorf FW, Luikart G (2007) Conservation and the genetics of populations, 1st edn. Blackwell Publishing Ltd, Malden, MA, USA

Bartley D, Bagley M, Gall G et al (1992) Use of linkage disequilibrium data to estimate effective size of hatchery and natural fish populations. Conserv Biol 6:365-375

Bonnet X, Naulleau G (1996) Catchability in snakes: consequences for estimates of breeding frequency. Can J Zool 74:233-239

Brassel KE, Reif D (1979) A procedure to generate Thiessen polygons. Geogr Anal 325:31-36

Castanet J, Guyetant R (1989) Atlas de répartition des Amphibiens et Reptiles de France. Société Herpétologique de France, Paris

Caughley G (1994) Directions in conservation biology. J Anim Ecol 63:215-244

Clark RW, Brown WS, Stechert R et al (2008) Integrating individual behaviour and landscape genetics: the population structure of timber rattlesnake hibernacula. Mol Ecol 17:719-730

Clement M, Posada D, Crandall KA (2000) TCS: a computer program to estimate gene genealogies. Mol Ecol 9:1657-1660 
Corbett K (1989) Conservation of European reptiles and amphibians. SEH, IUCN, London

Cornuet JM, Luikart G (1996) Description and power analysis of two tests for detecting recent population bottlenecks from allele frequency data. Genetics 144:2001-2014

di Rienzo A, Peterson AC, Garza JC et al (1994) Mutational processes of simple-sequence repeat loci in human populations. Proc Natl Acad Sci U S A 91:3166-3170

Excoffier L, Laval G, Schneider S (2005) Arlequin ver. 3.0: an integrated software package for population genetics data analysis. Evol Bioinform Online 1:47-50

Frankham R (1995) Effective population-size adult population size ratios in wildlife - a review. Genet Res 66:95-107

Frankham R (1996) Relationship of genetic variation to population size in wildlife. Conserv Biol 10:1500-1508

Frankham R (2005) Genetics and extinction. Biol Conserv 126: $131-140$

Frankham R, Ballou JD, Briscoe DA (2002) Introduction to conservation genetics. Cambridge University Press, Cambridge, UK

Fu YX (1997) Statistical tests of neutrality of mutations against population growth, hitchhiking and background selection. Genetics 147:915-925

Gautschi B, Widmer A, Joshi J et al (2002) Increased frequency of scale anomalies and loss of genetic variation in serially bottlenecked populations of the dice snake, Natrix tessellata. Conserv Genet 3:235-245

Gibbs HL, Prior KA, Weatherhead PJ (1994) Genetic analysis of populations of threatened snake species using RAPD markers. Mol Ecol 3:329-337

Gibbs HL, Prior KA, Weatherhead PJ et al (1997) Genetic structure of populations of the threatened eastern massasauga rattlesnake, Sistrurus c. catenatus: evidence from microsatellite DNA markers. Mol Ecol 6:1123-1132

Goudet J (1995) FSTAT (version 1.2): a computer program to calculate F-statistics. J Hered 86:485-486

Hardy OJ, Vekemans X (1999) Isolation by distance in a continuous population: reconciliation between spatial autocorrelation analysis and population genetics models. Heredity 83:145-154

Hardy OJ, Vekemans X (2002) SPAGEDi: a versatile computer program to analyse spatial genetic structure at the individual or population levels. Mol Ecol Notes 2:618-620

Hartl D, Clark AG (1997) Principles of population genetics, 3rd edn. Sinauer Associates, Sunderland

Hewitt GM (1999) Post-glacial re-colonization of European biota. Biol J Linn Soc 68:87-112

Hofer U, Monney J-C, Dusej G (2001) Les reptiles de Suisse. Répartition, habitats, protection. Birkhäuser Verlag AG

Ischer A (1930) La Vipère péliade des Ponts de Martel. Le Rameau de Sapin du club jurassien 1:2-5

Jäggi C, Wirth T, Baur B (2000) Genetic variability in subpopulations of the asp viper (Vipera aspis) in the Swiss Jura mountains: implications for a conservation strategy. Biol Conserv 94:69-77

Kaufmann M (1893) Les Vipères de France: morsures-traitement. Asselin et Houzeau, Paris

Kumar S, Tamura K, Nei M (2004) MEGA3: integrated software for molecular evolutionary genetics analysis and sequence alignment. Brief Bioinform 5:150-163

Leimu R, Mutikainen P, Koricheva J et al (2006) How general are positive relationships between plant population size, fitness and genetic variation? J Ecol 94:942-952

Lougheed SC, Gibbs HL, Prior KA et al (1999) Hierarchical patterns of genetic population structure in black rat snakes (Elaphe obsoleta obsoleta) as revealed by microsatellite DNA analysis. Evolution 53:1995-2001
Luiselli L (1993) High philopatry can produce strong sexual competition in male adders, Vipera berus. Amphib Reptil $14: 310-311$

Madsen T, Shine R (1992) Sexual competition among brothers may influence offspring sex ratio in snake. Evolution 46:15491552

Madsen T, Stille B, Shine R (1996) Inbreeding depression in an isolated population of adders Vipera berus. Biol Conserv 75:113-118

Madsen T, Shine R, Olsson M et al (1999) Conservation biologyrestoration of an inbred adder population. Nature 402:34-35

Madsen T, Ujvari B, Olsson M (2004) Novel genes continue to enhance population growth in adders (Vipera berus). Biol Conserv 120:145-147

Manni F, Guerard E, Heyer E (2004) Geographic patterns of (genetic, morphologic, linguistic) variation: how barriers can be detected by using Monmonier's algorithm. Hum Biol 76:173-190

Mantel N (1967) Detection of disease clustering and a generalized regression approach. Cancer Res 27:209

Marshall TC, Slate J, Kruuk LEB et al (1998) Statistical confidence for likelihood-based paternity inference in natural populations. Mol Ecol 7:639-655

Monmonier MS (1973) Maximum-difference barriers-alternative numerical regionalization method. Geogr Anal 5:245-261

Monney J-C (1996) Biologie comparée de Vipera aspis L. et de Vipera berus L. (Reptilia, Ophidia, Viperidae) dans une station des Préalpes bernoises. Unpublished thesis, University of Neuchâtel, Switzerland, 179 pp

Moran PAP (1950) Notes on continuous stochastic phenomena. Biometrika 27:17-23

Neumeyer R (1987) Density and seasonal movements of the adder (Vipera berus L.) on a subalpine environment. Amphib Reptil 2:63-82

Ohta T, Kimura M (1973) Model of mutation appropriate to estimate number of electrophoretically detectable alleles in a finite population. Genet Res 22:201-204

Otis DL, Burnham KP, White GC et al (1978) Statistical inference from capture data on closed animal population. Wildl Monogr 62:7-135

Peel D, Ovenden JR, Peel SL (2004) NeEstimator: software for estimating effective population size. Queensland Government, Department of Primary Industries and Fisheries

Pinston H, Craney E, Pépin D et al (2000) Amphibiens et Reptiles de Franche-Comté. Atlas commenté de répartition. Groupe naturaliste de Franche-Comté, Besançon, France

Piry S, Luikart G, Cornuet JM (1999) BOTTLENECK: a computer program for detecting recent reductions in the effective population size using allele frequency data. J Hered 90:502-503

Prestt I (1971) An ecological study of the viper Vipera berus in southern Britain. J Zool 164:373-418

Prosser MR, Gibbs HL, Weatherhead PJ (1999) Microgeographic population genetic structure in the northern water snake, Nerodia sipedon sipedon detected using microsatellite DNA loci. Mol Ecol 8:329-333

Rice WR (1989) Analyzing tables of statistical tests. Evolution 43:223-225

Rousset F (1997) Genetic differentiation and estimation of gene flow from $F$-statistics under isolation by distance. Genetics 145:12191228

Saint Girons H (1980) Biogéographie et évolution des vipères européennes. C R Soc Biogéogr 496:146-172

Saint Girons H (1981) Quelques observations sur la dispersion des nouveau-nés chez Vipera berus et Vipera aspis dans le bocage atlantique (Reptilia: Viperidae). Amphib Reptil 2:269-272 
Sokal RR, Wartenberg DE (1983) A test of spatial autocorrelation analysis using an isolation-by-distance model. Genetics 105:219-237

Soulé ME (1986) Conservation biology: the science of scarcity and diversity. Sinauer Associates

Ujvari B, Madsen T, Kotenko T et al (2002) Low genetic diversity threatens imminent extinction for the Hungarian meadow viper (Vipera ursinii rakosiensis). Biol Conserv 105:127-130

Ursenbacher S, Monney JC (2003) Résultats de 5 années de suivi d'une population de Vipère péliade (Vipera berus) dans le Jura Suisse: estimation des effectifs et discussion des méthodes d'estimation. Bull Soc Herp Fr 107:15-25

Ursenbacher S, Carlsson M, Helfer V et al (2006) Phylogeography and Pleistocene refugia of the Adder (Vipera berus) as inferred from mitochondrial DNA sequence data. Mol Ecol 15:34253437

Van Oosterhout C, Hutchinson WF, Wills DPM et al (2004) MICROCHECKER: software for identifying and correcting genotyping errors in microsatellite data. Mol Ecol Notes 4:535-538
Viitanen P (1967) Hibernation and seasonal movements of the viper, Vipera berus berus (L.), in southern Finland. Ann Zool Fenn 4:472-546

Villarreal X, Bricker J, Reinert HK et al (1996) Isolation and characterization of microsatellite loci for use in population genetic analysis in the timber rattlesnake, Crotalus horridus. J Hered 87:152-155

Vitalis R, Couvet D (2001a) ESTIM 1.0: a computer program to infer population parameters from one- and two-locus gene identity probabilities. Mol Ecol Notes 1:354-356

Vitalis R, Couvet D (2001b) Two-locus identity probabilities and identity disequilibrium in a partially selfing subdivided population. Genet Res 77:67-81

Völkl W, Thiesmeier B (2002) Die Kreuzotter-ein Leben in festen Bahnen? Laurenti Verlag

Weir BS, Cockerham CC (1984) Estimating $F$-statistics for the analysis of population structure. Evolution 38:1358-1370 